REFERENCES

BACON, W. E., SNYDER, H. L., \& HULSE, S. H. Saccharine preference in satiated and deprived rats. Journal of Comparative \& Physiological Psychology, 1962, 55, 112-114.

GENTILE, R. L. Depression of intake by saccharin adulteration: The role of taste quality in the control of food intake. In $\mathrm{C}$. Pfaffman (Fd.). Olfaction and taste. New York: Rockefeller University Press, 1969. Pp. 601-607.

JACOBS, H. L. Taste and the role of experience in the regulation of food intake. In M. Sare and $O$. Maller (Eds.), The chemical senses and nutrition. Baltimore: Johns Hopkins Press, 1967. Pp. 187-200.

JACOBS, H. L., \& SHARMA, K. N. Taste versus calories: Sensory and metabolic signals in the control of food intake. Annals of the New York Academy of Science, 1969, 157, 1084-1125.

KAMEN, J. M., PILGRIM, F. J., GUTMAN, N. J., \& KROLL, B. J. Interactions of suprathreshold taste stimuli. Journal of Experimental Psychology, 1961, 62, 348-356.

LeMAGNEN, J. Le processus de discrimination par le rat blanc des stimuli sucres alimentaires et non alimentaires. Journal de Physiologie 1954, 46, 414-418.

PFAFFMAN, C., YOUNG, P. T., DETHIER, V. G., RICHTER, J. P., \& STELLAR, F. The preparation of solutions for research in chemoreception and food acceptance. Journal of Comparative \& Physiological Psychology, 1954, 47, 93-96.

SMITH, M., \& DUFFY, M. Consumption of sucrose and saccharine by hungry and satiated rats. Joumal of Comparative \& Physiological Psychology, 1957, 50, 65-69.

VALENSTEIN, E. S. Selection of nutritive and non-nutritive solutions under different conditions of need. Journal of Comparative \& Physiological Psychology, 1967, 63, 429-433. VALENSTEIN, E. S., COX, V. C., \& KAKOLEWSKI, J. W. Polydipsia elicited by synergistic action of a saccharin and glucose solution. Science, $1967,157,552-554$.

WADE, G. N., \& ZUCKER, I. Taste preferences of female rats: Modification by neonatal hormones, food deprivation, and prior experience. Physiology \& Behavior, 1969, 4, 935-943.

\title{
The effect of ACTH administration upon activity-related self-starvation*
}

\author{
GEORGE F. STRUTT and CHARLES N. STEWART \\ Franklin and Marshall College, Lancaster, Pa. 17604
}

All Ss lived on a 23-h food-deprivation schedule. Two experimental groups lived in activity wheels while two control groups lived in laboratory cages. One experimental and one control group received subcutaneous injections of ACTH, while the other two groups received injections of physiological saline. The ACTH injection had no effect on the self-starvation phenomenon, and the results are in opposition to the hypothesis of adrenocortical involvement in the phenomenon.

It has been reported by Routtenberg $\&$ Kuznesof (1967) that rats confined to activity wheels and living on a $23-\mathrm{h}$ food-deprivation schedule show an increase in activity, a decrease in body weight, and a food consumption less than that of control Ss living in standard laboratory cages on the same deprivation schedule. This "self-starvation" phenomenon was replicated by Strutt \& Stewart (1970). Routtenberg (1968) proposed that two factors are operative in this phenomenon, "deprivation stress" and "novelty stress,"

* This research was supported by National Science lioundation Undergraduate Research Program Grant GY-4295. and hypothesized that the endocrine system, in particular the adrenal cortex, may play an important role in the response of Ss to these stressors.

Strutt \& Stewart (1970) hypothesized that the proposed adrenocortical response of experimental Ss might involve an increased output of glucocorticoids that would, by means of gluconeogenesis, make glucose available which would perhaps facilitate running and suppress food consumption (Mayer, 1953). The blood glucose levels of experimental Ss did not follow the predictions concerning an adrenocortical response-driven phenomenon and were found to be significantly lower in the active Ss.

To test the hypothesis of adrenal involvement more directly, an attempt was made in the present study to produce an increased adrenocortical response by exogenous administration of ACTH. If this physiological mechanism was "driving" the self-starvation phenomenon, then those Ss injected with ACTH should show an earlier and perhaps more dramatic increase in activity and suppression of eating when compared to saline-injected experimentals. This would lead to much quicker self-starvation in the ACTH-injected experimental Ss.

\section{METHOD}

Thirty-two male Sprague-Dawley rats, bred in the Franklin and Marshall laboratory, served as Ss. They were 81.93 days of age and weighed $292-439 \mathrm{~g}$ at the beginning of the experiment. Water was available ad lib to all $\mathrm{Ss}$.

Sixteen Wahmann activity wheels, the home room, feeding room, and diet were identical to those reported by Strutt \& Stewart (1970). The home-room temperature was maintained at $72^{\circ} \pm 4^{\circ} \mathrm{F}$.

The preexperimental treatment procedure was the same as described by Strutt \& Stewart (1970). Six days before the onset of the experimental procedures the Ss were divided into two equal groups, balanced according to body weight and litter affiliation. One group received 0.5 USP units of corticotropin injection (ACTH)/ $100 \mathrm{~g}$ of body weight. The ACTH was placed in a $12.5 \%$ concentration in physiological saline and injected subcutaneously in the nape of the neck, $.05 \mathrm{cc} / 100 \mathrm{~g}$ of body weight. The other group received control injections of physiological saline, also $.05 \mathrm{cc} / 100 \mathrm{~g}$ of body weight. These injections were given $7 \mathrm{~h}$ after light onset and were continuer

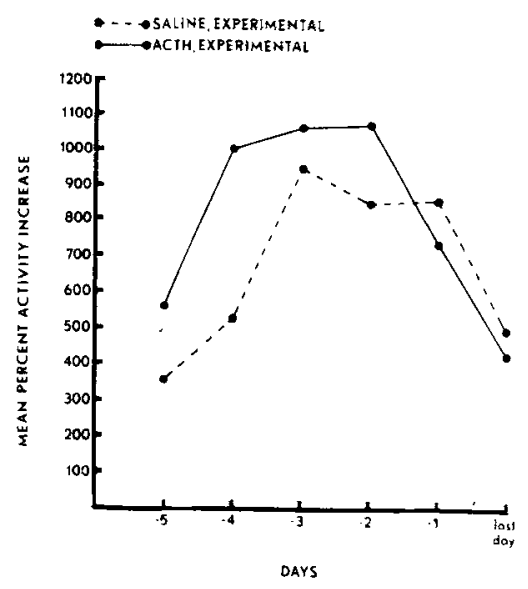

Fig. 1. Mean percent of activity increase of the experimental groups over the last 6 days of the study for each $S$. 


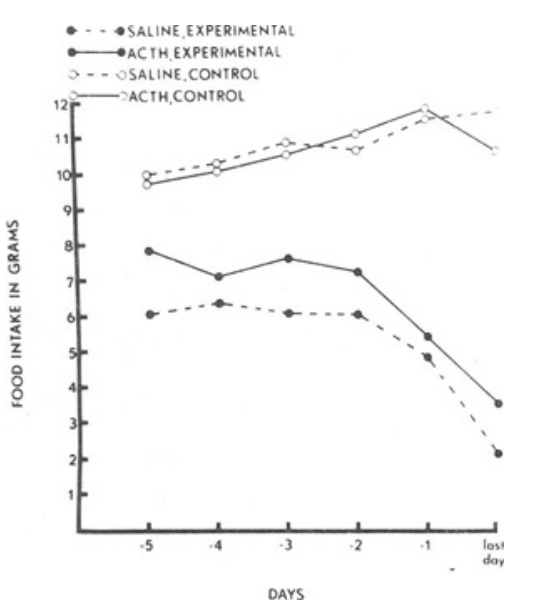

Fig. 2. Mean food intake in grams of experimental and control groups over the last 6 days of the study for each $S$.

throughout the experiment. On the 6th day each injection group was divided into two equal groups balanced according to body weight and litter affiliation. One group from each condition began living in individual activity wheels, while the remaining two groups lived in standard laboratory cages.

All $\mathrm{Ss}$ were fed for $1 \mathrm{~h}$ daily during the 6 th $\mathrm{h}$ after light onset. At the end of each daily feeding period, each $\mathrm{S}$ was given his appropriate injection, based on the body weight recorded immediately before that day's feeding period. Activity, food intake, and water intake were recorded daily. The criterion of weight stabilization, described by Routtenberg \& Kuznesof (1967) was used, and the study ended when all Ss either maintained weight or died. After death or weight stabilization, the adrenal glands of each $S$ were removed and weighed to the nearest $0.1 \mathrm{mg}$.

\section{RESULTS}

Three Ss were eliminated from the study: One $S$ died during predeprivation $\mathrm{ACTH}$ administration, one $\mathrm{S}$ escaped from the activity wheel and one $S$ was eliminated due to otitis interna.

Five of six ACTH experimental $\mathrm{Ss}$ died (mean, 13.2 days) while one $S$ main tained weight in 20 days. $\mathrm{Al}_{1}^{1}$ saline experimental Ss starved (mean, 13.5 days), while all

Table 1

Mean Adrenal Gland Weights (Combined, in Milligrams) and Mean Adrenal

Gland/Body Weight Ratios

\begin{tabular}{lcc}
\hline \multicolumn{1}{c}{ Group } & $\begin{array}{c}\text { Mean } \\
\text { Gland } \\
\text { Weight }\end{array}$ & $\begin{array}{c}\text { Mean Gland } \\
\text { Weight/Body } \\
\text { Weight }\end{array}$ \\
\hline ACTH Control & 53.40 & .2113 \\
ACTH Experimental & 66.48 & .2985 \\
Saline Control & 34.31 & .1267 \\
Saline Experimental & 49.44 & .2233 \\
\hline
\end{tabular}

ACTH control Ss maintained weight (mean, 24.25 days) and all saline control Ss maintained weight (mean, 21.86 days).

Figure 1 shows the percent increase in activity over the last 6 days of the study. Analysis according to Myers (1966, p. 189) indicated a significant effect of days $(\mathrm{F}=6.40, \quad \mathrm{df}=5 / 70, \quad \mathrm{p}<.01)$ but no significant treatments or interaction effect. This same result emerges if the analysis is done on the raw activity scores. The two experimental groups did not differ significantly on their first-day activity scores.

The body weight of experimental Ss drops sharply over the last 6 days, while the body weight of control Ss falls very gradually and then rises. There is a significant days effect $(F=123.76$, $\mathrm{df}=5 / 125, \quad \mathrm{p}<.01)$ and a significant Experimental vs Control by Days interaction $(F=87.76, \quad \mathrm{df}=5 / 125$, $\mathrm{p}<.01)$. A significant ACTH vs saline effect is clearly not present.

The mean food intake data is presented in Fig. 2. A significant suppression of food intake by experimental Ss is clearly present ( $F=51.72$, df $=1 / 25, p<.01)$, but no ACTH vs saline effect is present. A significant days effect is present $(F=6.20$, $\mathrm{df}=5 / 125, \mathrm{p}<.01)$, and there is a significant Experimental vs Control by Days interaction effect $\quad(F=15.69$, $\mathrm{df}=5 / 125, \mathrm{p}<.01)$.

The total water intake of experimental Ss decreased over the last 6 days of the study, especially over the last 3 days, while the water intake of control Ss remained relatively constant. A significant days effect is present $(F=63.20, \mathrm{df}=1 / 25$, $\mathrm{p}<.01$ ) and there is a significant Experimental vs Control by Days interaction $(F=47.78, \mathrm{df}=1 / 25, \mathrm{p}<.01)$. Again there was no significant ACTH vs saline effect.

The mean adrenal gland weights and adrenal gland/body weight ratios are presented in Table 1. A two-way analysis of variance performed on the adrenal weights indicated a significant ACTH vs saline effect $(F=26.73, d f=1 / 25$, $\mathrm{p}<.01)$ and a significant experimental vs control effect $(F=16.29, \quad d f=1 / 25$, $\mathrm{p}<.01)$. Post hoc analyses by Scheffé test showed that the adrenal weights of experimental Ss were significantly greater in both the ACTH and saline conditions, and the adrenal weights of ACTH-injected Ss were significantly greater within the experimental groups and within the control groups. These same differences emerged when analysis was conducted on the adrenal-weight/body-weight ratios.

\section{DISCUSSION}

The results obtained indicate that the self-starvation phenomenon is not affected by the ACTH administration at the dosage level used in this study (0.5 USP units $/ 100 \mathrm{~g}$ ), although the dosage was sufficient to produce a significant increase in adrenal gland weight in both experimental (34.5\%) and control (55.6\%) Ss. It cannot be argued, therefore, that the dosage of ACTH selected was ineffective in stimulating increased adrenocortical activity. Hence, the data do not support the hypothesis that novelty and deprivation stress-induced activation of the pituitary-adrenocortical system are responsible for the suppression of food intake in the active animals. That adrenocortical function may be augmented by activity remains a possibility, since we did find significant increases in adrenal gland weights of active animals both in the case of those receiving ACTH (24.5\%) and those receiving saline $(44.1 \%)$. The role, if any, which this adrenal hypertrophy may play in the self-starvation phenomenon remains obscure, however, since self-starvation did not occur in controls given ACTH in spite of the $55.6 \%$ increase in gland weight. Experimental animals given the hormone did not self-starve any earlier than those given saline.

The findings of Russek et al (1968) suggest, however, that a conditioned adrenal medullary response may be a mechanism operative in the self-starvation phenomenon. Using fasted dogs (22-23 h), it was reported that a prolonged epinephrine-induced anorexia ( $45 \mathrm{~min}-2 \mathrm{~h}$ ) could be conditioned to the experimental situation. However, it was not possible to condition the mild hyperglycemia that normally accompanied the epinephrine-induced anorexia. Predictions stemming from this adrenal medullary mechanism are consistent with the reports of the mitigating effects of adaptation to the feeding room (Routtenberg \& Kuznesof, 1967) and chlorpromazine (Routtenberg, 1968) on self-starvation. REFERENCES

MAYER, J. Glucostatic mechanism of regulation of food intake. New England Medical Journal, 1953, 249, 13-16.

MYERS, J. Fundamentals of experimental design. Boston: Allyn and Bacon, 1966.

ROUTTENBERG, A. Self-starvation of rats living in activity wheels: Adaptation effects. Journal of Comparative \& Physiological Psychology, 1968, 66, 234-238.

ROUTTENBERG, A., \& KUZNESOF, A. W. Self-starvation of rats living in activity wheels on a restricted feeding schedule. Journal of Comparative \& Physiological Psychology, 1967, 64, 414-424.

RUSSEK, M., RODRIGUEZ-ZENDEJAS, A, M., \& PINA, S. Hypothetical liver receptors and the anorexia caused by adrenaline and glucose. Physiology \& Behavior, 1968, 3. 249-257.

STRUTT, G. F., \& STEWART, C. N. The role of blood glucose in activity related self-starvation. Psychonomic Science, 1970, 18, 287-289. 